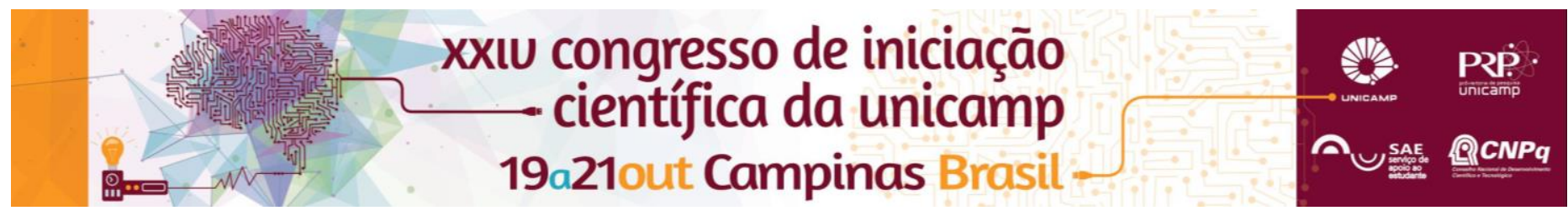

\title{
Análise sensorial de pães de forma convencionais incorporados de farinha de trigo sarraceno
}

\section{Marcelo Alex de Lima Rodrigues*, Lara Tatiane Geremias Ferreira Brites, Caroline Joy Steel}

\section{Resumo}

O trigo sarraceno (Fagopyrum esculentum) tem sido apontado como uma alternativa à substituição da farinha de trigo na indústria alimentícia devido à sua rica composição de nutrientes, podendo assim ser um potencial ingrediente em formulações enriquecidas. Este trabalho apresentará a aceitação sensorial de pães de forma incorporados de $0,30 \mathrm{e}$ $45 \%$ de farinha de trigo sarraceno refinada ou de grão inteiro.

Palavras-chave: trigo sarraceno, análise senorial, teste de aceitação.

\section{Introdução}

O trigo sarraceno é um grão que possui muitos benefícios nutricionais, sendo sua farinha utilizada em misturas de panquecas, massas para bolos, tortas, e também na incorporação com farinha de trigo comum para a elaboração de pães e massas alimentícias.

Muitos estudos demonstraram que a farinha de trigo sarraceno possui efeitos benéficos para a saúde humana e na prevenção de doenças, devido ao seu teor de compostos fenólicos. ${ }^{2}$

Este trabalho teve como objetivo estudar a substituição parcial de 30 ou $45 \%$ da farinha de trigo (FT) por farinha de trigo sarraceno refinada (FSR) ou farinha de trigo sarraceno de grão inteiro (FSG) em pães de forma (formulações elaboradas: padrão 100\% FT; F1 30\% FSR; F2 45\% FSR; F3 30\% FSG; e F4 45\% de FSG) e avaliar a sua aceitação sensorial.

\section{Resultados e Discussão}

Participaram da análise sensorial 116 provadores não treinados de ambos os sexos, com idades de 17 a 59 anos, que avaliaram, através da escala hedônica de 9 pontos, os atributos: aparência do miolo, cor do miolo, aroma, sabor, textura e impressão global.

Na Figura 1, é apresentado o gráfico aranha das médias das notas dos provadores por atributo para cada amostra.

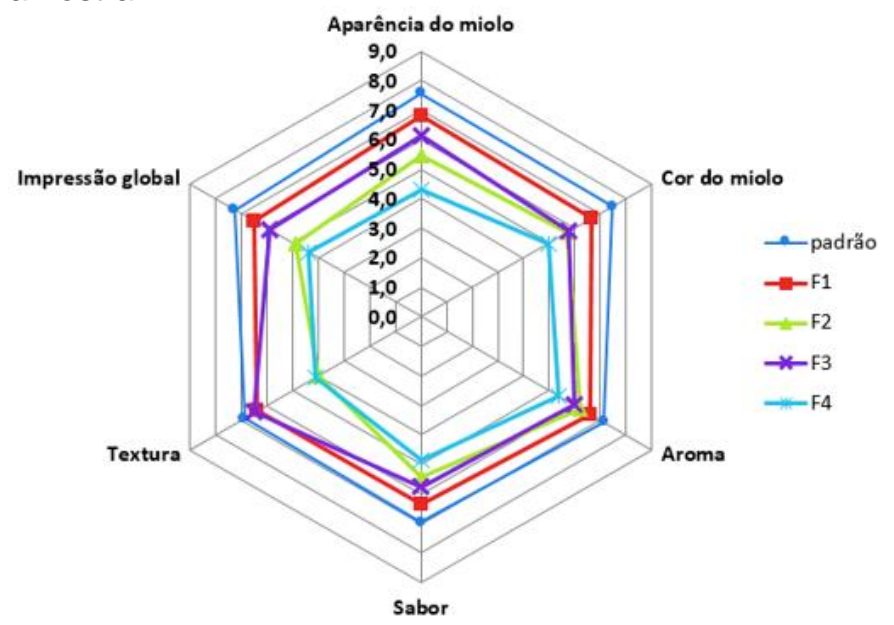

Figura 1. Gráfico aranha das notas médias dos provadores por atributos e amostra avaliada.
Considerando que as amostras com $70 \%$ de aprovação (notas acima de 6,3) são aceitas e, levandose em consideração apenas a impressão global, as amostras Padrão, F1 e F3 foram aceitas sensorialmente.

A amostra padrão foi a que obteve as melhores médias em todos os atributos, seguida pelas amostras F1, F3, F2 e F4, consecutivamente. A amostra F1 (70\% FT e 30\% FSR) e a amostra F3 (70\% FT e 30\% FSG), apesar de apresentarem diferenças na farinha de trigo sarraceno incorporada (uma refinada e outra de grão inteiro) tiveram notas muito próximas para os atributos aroma, sabor, textura e impressão global.

A incorporação de até $30 \%$ de FSR ou FSG (F1 e F3) foi a que mais contribuiu com os atributos aroma e textura dos pães, já que as médias de notas desses atributos apresentaram menores variações entre si (notas de 6,0 a 7,1 para aroma; e 6,5 a 6,9 para textura), além de apresentarem comentários positivos dos provadores, como aroma suave e textura agradável.

As amostras F2 e F4 apresentaram notas menores que 6,3 para todos os atributos avaliados, não obtendo aceitação sensorial. Dentre os atributos mais afetados com a incorporação de $45 \%$ de FSR ou FSG estão aparência do miolo, textura e impressão global, sendo que 0 atributo textura de ambas as amostras recebeu diversos comentários em que os provadores julgavam as amostras como muito secas.

\section{Conclusões}

Podemos concluir que as amostras com incorporação de até $30 \%$ de FSR ou FSG foram aceitas sensorialmente, o que viabiliza a produção de pães com incorporação de nutrientes oriundos do trigo sarraceno.

Podemos concluir também que a incorporação de até $30 \%$ de FSR ou FSG não afetou negativamente a aceitação do aroma e da textura dos pães.

\section{Agradecimentos}

Agradecimentos ao Programa de Formação Interdisciplinar Superior (ProFIS) e ao Serviço de Apoio ao Estudante (SAE) pela bolsa concedida.

${ }^{1}$ ROBINSON, R.G. (1980): The buckwheat crop in Minnesota. Agr. Exp. Sta. Bul 539, Univ. Minnesota, St. Paul.

${ }^{2}$ ZHANG Z. et al. Inhibitory Activity and thermostability of a-amylase-inhibitor from buckwheat flour. Proceedings of the 9th international symposium on buckwheat, Prague 2004, Czech Republic. 